\title{
Impact of Somatic Symptoms on Identification of Depression among General Outpatients by Family Physicians in North-Western Nigeria
}

\author{
Auwal Sani Salihu1,2 \\ ${ }^{1}$ Department of Psychiatry, Bayero University, Kano, Nigeria \\ ${ }^{2}$ Aminu Kano Teaching Hospital, Kano, Nigeria \\ Email: auwal01@yahoo.com
}

Received 10 April 2015; accepted 5 June 2015; published 8 June 2015

Copyright (C 2015 by author and Scientific Research Publishing Inc. This work is licensed under the Creative Commons Attribution International License (CC BY). http://creativecommons.org/licenses/by/4.0/

(c) (i) Open Access

\section{Abstract}

In many places in the world, General Practitioners are only able to identify depression in a small fraction of depressed patients presenting to general outpatient department. The effect of somatic symptoms on its recognition was investigated. The study determines the identification rate of depression by general practitioners among outpatients with somatic symptoms and those without somatic symptoms. This descriptive cross sectional study was conducted in Family Medicine Department, Aminu Kano Teaching Hospital, Kano, Nigeria. The Hospital Anxiety and Depression Scale (HADS) was used to screen selected participants. Forms were used by GPs to itemize medical and psychiatric symptoms elicited as well as medical and psychiatric diagnoses made. Schedule for Clinical Assessment in Neuropsychiatry (SCAN) version 2.1, was used to confirm the diagnosis of depression. Hamilton Depression Rating Scale (HDRS) was used for severity using items 11-14 of Hamilton Depression Rating Scale. Those with somatic symptoms score of 1-3 were rated as having low and those with 4-10 were rated as having high. Of the 410 outpatients recruited, 402 participated in the study. Two hundred and thirteen were screened depressed (HADS). Two hundred were confirmed depressed using SCAN (49.8\%). The GPs identified $31.3 \%$ of those participants diagnosed depressed without somatic symptoms compared to $15.2 \%$ of those who were diagnosed depressed with somatic symptoms. However, no significant association was found between GPs ability to identify depression in the presence or absence of somatic symptoms $(p=$ 0.09). This study found no association between GPs ability to identify depression and presence or absence of somatic symptoms $\left(\chi^{2}=2.75, p=0.09\right)$. However, this study found that the higher the level of somatic symptoms the more unlikely it's for GPs to identify depression. To reduce the burden of depression by early detection and treatment, continuing medical education of GPs should include skills in identification of depression. 


\section{Keywords}

\section{Depression, General Outpatients, General Practitioners, Nigeria, Identification, Somatic Symptoms}

\section{Introduction}

Depression which is a psychological disorder that affects person's mood, bodily functions and social interactions makes a large contribution to the global burden of disease [1]. Globally, it is the leading cause of disability as measured using YLDs (years-lived with-disability) and the $4^{\text {th }}$ leading contributor to the burden of disease as measured by DALYs (disability-adjusted life-years) in 2000 [1]. It is projected that in 2020, depression will reach $2^{\text {nd }}$ place of the ranking of DALYs calculated for all ages and both sexes [1]. Today, depression is already the $2^{\text {nd }}$ cause of DALYs in the very productive age category $15-44$ years for both sexes combined [2]. While it already occupies the first place among the causes of DALYs in high income countries, it is in the $8^{\text {th }}$ place among the ten topmost causes of DALYs [1] in low income countries, though this is due to preponderance of (group I) communicable, maternal, peri-natal and nutritional conditions. More so, it is projected to increase by sixty-six percent by the year 2030, thus representing a greater burden of disease than communicable, maternal, peri-natal and nutritional conditions in these countries [2] which include Nigeria. Despite this enormous burden at present and the projection in future, depression is under-diagnosed and under-treated by General Practitioners (GPs) that are expected to consult, diagnose as well as treat majority (up to 90\%) of depressed patients [3] [4]. Depression in family practice has been studied by many authors in Nigeria [4]-[6] and other parts of the world [7]. Some of them concentrated on its prevalence only along with other psychiatric morbidities [7] [8] and others included its correlates [9]. Many reported if not all that depression was very common among general outpatients. However, some studies noted very low recognition of depression by general practitioners (GPs). It was reported by Uwakwe in 2004 that only 10.9\% of patients with depression were recognised in private general practice in Aguata, Nigeria [5], and Xiaoxia et al. reported as low as $4 \%$ in a multi-centred study comprising of 23 general hospitals outpatient departments in Shenyang, China [10].

However, those that studied recognition of depression among general outpatients by GPs reported underrecognition and under-treatment. Some reasons were given, among which was the presence of somatic symptoms as distraction to GPs from recognizing depression [7] [10] [11]. Studies conducted elsewhere such as the work of Kirmayer et al. in two Canadian University-affiliated family medicine teaching units concluded that while physician recognition of psychiatric distress in primary care varied widely, there was the same pattern of reduction with increasing level of somatic symptoms [12]. Despite evidence of significant impact of somatic symptoms on identification of depression by GPs, there is still paucity of information in Nigeria about whether the presence of somatic symptoms or its absence influences the diagnosis of depression among general outpatients by GPs. Therefore, this study seeks to investigate the impact of somatic symptoms on the recognition of depression among general outpatients by GPs.

\section{Materials and Method}

The study was conducted at Aminu Kano Teaching Hospital (AKTH). The Hospital was established to serve as a fully functional 500-bed teaching hospital for the needs of the local and wider community. It is located in Kano North-Western, Nigeria. The hospital provides specialist and general medical services to patients from Kano metropolis and the various Local Government Areas surrounding it. Kano Metropolis has a population of about 2.2 million. The Department of Family Medicine is located in accessible part of the hospital. The department is the first-port-of-call for non-emergency cases before referral to specialist clinics. It is a very busy department, with an average of 600 new adult patients being registered during working days every week. The morning session sees about 120 of these patients daily. The yearly average newly registered patient attendance is about 32,000 .

The study design is a descriptive cross-sectional study. The study sample size was calculated based on the objective of determining the prevalence of depression among general outpatients using the formula

$$
N=z^{2} p q / E^{2} \quad[13]
$$


where $N=$ minimum sample size, $Z=1.96$ (standard normal deviate for 95\% confidence interval level), $p=$ proportion of population with condition studied (59.6\%) [10], $q=$ complementary probability $=(100-P)=(100$ $-59.6)=40.4 \%, E=$ precision required (tolerable sampling error) $=5 \%$. Therefore, $N=1.96^{2} \times 59.6(100-$ $59.6) / 5^{2}=369.998$, approximately $=370$. Given attrition rate of $10 \%=370+10 / 100(370)=407 \approx 410$.

\subsection{Ethical Approval}

An approval for the study was obtained from the Research Ethics Committee of the AKTH, Kano State Nigeria.

\subsection{Inclusion/Exclusion Criteria}

No patient was forced to participate in this study against his/her wish. Participation was entirely voluntary. All newly registered adults (because physicians may not attempt to make new diagnosis after the initial one and to avoid re-selecting same patient on follow up visit after initial participation) patients who were equal or over 18yrs old on self-initiated visit, who gave consent and can read and write English or Hausa. Patients who were receiving treatment for any psychiatric disorder, those who declined to give consent, those too ill to take part and those who cannot read and write English or Hausa were excluded.

\subsection{Declaration of Interest}

The study was sponsored by the Aminu Kano Teaching Hospital as part of the mandatory residency training dissertation sponsorship.

\subsection{Sampling}

The sample was drawn using systematic random sampling method from all the patients who attended the general outpatient clinic for the first time, who met inclusion criteria and accepted to take part in the study. The list of all the newly registered patients formed the sampling frame. The study commenced from $1^{\text {st }}$ September to beginning $1^{\text {st }}$ November 2011.

\subsection{Procedure}

A pre-tested questionnaire (English/Hausa) containing socio-demographic information about the patient incorporated to HADS (hospital anxiety and depression rating scale (English/Hausa) was used to screen for depression. The Hamilton Depression Scale (HDS or HAMD or HDRS) was used to measure the severity of depressive symptoms in those confirmed to depressed [14]. Items 11-14 that measure somatic symptoms were used to rate the somatic symptoms. Schedule for Clinical Assessment in Neuropsychiatry (SCAN) [15] version 2.1. A specially designed form containing four items asking the consulting physician to state the patient's presenting complaints, the medical diagnoses if any, symptoms of mental illness and the psychiatric diagnosis if present was also used.

Four hundred and ten patients were selected from newly registered patients on self initiated visit attending out-patients clinic for the first time during the study period of eight weeks. All patients attending the clinic who were aged 18years and above, who satisfied the inclusion criteria of this study were invited to participate. The SCAN interview was conducted by the researcher. Diagnoses generated by the SCAN software. Data was analyzed using the Statistical Package for Social sciences (SPSS) software for windows version 16 [16]. Proportions, percentages and ratios were determined as applicable. Classification into depressed and non-depressed categories was done based on SCAN interview result. Grading into mild, moderate and severe depression was additionally based on Hamilton depression rating scale (HDRS) and grouping into low, high and No somatic symptoms were based on the scores in the somatic items in HDRS. The educational level of the participants was sub-grouped into low level (secondary) and tertiary (post-secondary). Chi square test was used to determine significant association between variables. Chi square test with Yate's correction was also applied where appropriate. Level of significance was set at $\mathrm{p}<0.05$ two tails.

\section{Result}

In all, four hundred and ten (410) patients were selected for the study. However, 402 (98.1\%) of them finally 
participated. Two hundred were confirmed depressed using SCAN (49.8\%). Table 1 shows that out of the 200 participants who satisfied the ICD10 criteria for the diagnosis of depression, the Family Physicians (FPs) were able to identified only 33 (16.5\%). The FPs identified more of the depressed participants who were 45 years and younger $(19.1 \%)(p=0.275)$, were able to identify a higher percentage of depressed male participants $(18.5 \%)$ compared with depressed female participants $(15.6 \%)(\mathrm{p}=0.604)$, and identified more of those $(26.5 \%)$ with tertiary education compared to those with lower level of education $(13.3 \%)(\mathrm{p}=0.029)$. They identified about same proportion of employed (17.2\%) and unemployed (16.2\%) depressed participants ( $\mathrm{p}=0.857)$. They identified $37.5 \%$ of those who had positive family history of mental illness compared with $16.5 \%$ of those who had negative family history of mental illness. However, the observed difference was not statistically significant $(\mathrm{p}=$ 0.792). There was no difference in their ability to identify depression among those with history of substance abuse or chronic medical conditions. Table 2 shows that more depressed participants without somatic symptoms were identified by the FPs (31.3\%) compared with depressed participants who had somatic symptoms (15.2\%). However, there was no statistically significant difference $(p=0.09)$. Table 3 showed that among depressed participants with somatic symptoms, the family physicians were able to identified $46.2 \%$ with low score compared with $10.1 \%$ who had high score and difference was statistically significant $(\mathrm{p}=0.001)$.

Table 1. Socio-demographic profile of family physicians’ identified depressed participants.

\begin{tabular}{|c|c|c|c|c|}
\hline Factors & $\begin{array}{l}\text { Family physicians’ } \\
\text { identified cases n (\%) }\end{array}$ & $\begin{array}{c}\text { Family physicians' } \\
\text { unidentified cases n (\%) }\end{array}$ & $\chi^{2}$ & $\mathrm{p}$ \\
\hline \multicolumn{5}{|l|}{ Age } \\
\hline$\leq 45$ & $21(19.1)$ & 89 (80.9) & $1.19^{* *}$ & 0.275 \\
\hline$>45$ & $12(13.3)$ & 78 (86.7) & & \\
\hline \multicolumn{5}{|l|}{ Gender } \\
\hline Male & 12 (18.5) & $53(81.5)$ & $0.27^{* *}$ & 0.604 \\
\hline Female & $21(15.6)$ & $114(84.4)$ & & \\
\hline \multicolumn{5}{|l|}{ Marital status } \\
\hline Married & $20(15.5)$ & $109(84.5)$ & $0.26^{* *}$ & 0.609 \\
\hline Unmarried & $13(18.3)$ & $58(81.7)$ & & \\
\hline \multicolumn{5}{|l|}{ Educational status } \\
\hline Lower level (secondary) & $20(13.3)$ & $131(86.7)$ & $4.74^{*}$ & 0.029 \\
\hline Tertiary level (post secondary) & $13(26.5)$ & 36 (73.5) & & \\
\hline \multicolumn{5}{|l|}{ Employment status } \\
\hline Employed & $10(17.2)$ & $48(82.8)$ & $0.03^{* *}$ & 0.857 \\
\hline Unemployed & $23(16.2)$ & $119(83.8)$ & & \\
\hline \multicolumn{5}{|l|}{ Family history (FH) } \\
\hline Positive FH & $3(37.5)$ & $15(62.5)$ & $0.10^{* *}$ & 0.792 \\
\hline Negative FH & $30(16.5)$ & $152(83.5)$ & & \\
\hline \multicolumn{5}{|l|}{ Substance use } \\
\hline None & $32(16.9)$ & $157(83.1)$ & $0.88^{* *}$ & 0.350 \\
\hline Use substances & $1(9.1)$ & $10(90.9)$ & & \\
\hline \multicolumn{5}{|l|}{ Chronic medical condition } \\
\hline None & $4(12.5)$ & $28(87.5)$ & $0.16^{* *}$ & 0.685 \\
\hline Present & $29(17.3)$ & $139(82.7)$ & & \\
\hline
\end{tabular}

"Significant $(\mathrm{p}<0.05),{ }^{* *}$ Not significant $(\mathrm{p} \geq 0.05)$. 
Table 2. Family physicians’ identified/unidentified depressed cases and presence/absence of somatic symptoms.

\begin{tabular}{|c|c|c|c|c|}
\hline Somatic symptoms & Family physicians’ identified cases n (\%) & Family physicians’ unidentified cases n (\%) & $\chi^{2}$ & $\mathrm{p}$ \\
\hline Present & $28(15.2)$ & $156(84.8)$ & $2.75^{*}$ & 0.09 \\
\hline Absence & $5(31.3)$ & 11 (68.7) & & \\
\hline
\end{tabular}

${ }^{* *}$ Not significant $(\mathrm{p} \geq 0.05)$.

Table 3. Family physicians’ identified/unidentified depressed cases and low/high of somatic symptoms.

\begin{tabular}{ccccc}
\hline Somatic symptoms & Family physicians' identified cases n (\%) & Family physicians’ unidentified cases n (\%) & $\chi^{2}$ & p \\
\hline Low score & $12(46.2)$ & $14(53.8)$ & $22.46^{*}$ & 0.001 \\
High score & $16(10.1)$ & $142(89.9)$ & \\
\hline
\end{tabular}

*Significant $(\mathrm{p}<0.05)$.

\section{Discussion}

About one sixth of the depressed patients were identified as depressed by FPs in this study. Thus, the identification rate among FPs was $16.5 \%$. This rate was much higher than the rate of $4 \%$ reported by Alan et al. [2] However, the rate in the present study is lower than one third reported by Xiaoxia et al. [6] Other studies have reported rates of $27.9 \%$ [17] and even $64 \%$ by Simon et al. among general outpatients [18] though convenient sampling was used to recruit participants in the study.

The socio-demographic factors of those identified by FPs and those who were not were compared in this study. Only education was found to be associated with increased FPs recognition of depression. Age and gender had no association with FPs identification. These findings were similar to that of Kirmayer et al. [12] More than three quarter (179) of the depressed patients were found to have had somatic symptoms. This was consistent with the previous report of Gureje et al. that somatization is a common problem in primary care across cultures. [7] Afolabi et al. [9] and Okulate [6] reported that $69.2 \%$ and $88 \%$ of general outpatients had somatic symptoms. Among the $92.5 \%$ of the depressed patients with somatic symptoms only about one sixth were identified by FPs while among $7.5 \%$ that were depressed without somatic symptoms up to one third were identified as depressed by the FPs. However, while there was no significant difference between FPs ability to identified depression in the presence and absence of somatic symptoms $(\mathrm{p}=0.090)$, there was an observable trend of FPs identification of lower proportion of the depressed with somatic symptoms compared to the high proportion among those without somatic symptoms.

A further analysis of the FPs ability of identifying depression among those patients with low and high rate of somatic symptoms showed a significant association between the rates and the ability to identify $(p=0.001)$. This finding implied that the more the rate of somatic symptoms in a depressed patient the more difficult it was for FPs to identify depression. Similar finding was reported by Kirmayer et al. [12] that increasing level of somatization substantially reduces as well as delay the rate of recognition of depressed general outpatients by family physicians.

\section{Limitations}

Limitations of this study include: 1) This was a descriptive cross-sectional study design and therefore causal relationships cannot be attributed. 2) The prevalent misconception in Kano that there is high mortality rate in the teaching hospital may have influences the nature of patients utilizing the services. Thus people with some level of education are likely to appreciate that teaching hospitals are referral centre where terminal cases are disproportionate. Hence, less educated patients may have aversion for the centre where the study was carried out.

\section{Conclusion and Recommendations}

Depression was very common among general outpatients and family physicians' identification was very low. The study also revealed that FPs' ability to identify depression was not affected by mere presence or absence of somatic symptoms, though a trend of low identification in the presence of somatic symptoms was observed. However, the rate of somatic symptoms significantly associates with FPs ability to identify depression among 
general outpatients. In order to reduce the burden of depression and its impact on quality of life in family practice clinics, there is a need for family physicians to deliberately look out for depression especially in the presence of somatic symptoms. Therefore, some recommendations are hereby made: 1) Prevalence of depression among general outpatients is very high. Therefore, family physicians should make effort to lookout for depression; 2) Family physicians need to have high index of suspicion in patient with somatic symptoms to detect depression; 3) Use of very brief screening instrument tool for depression like PHQ 2 should be popularized among medical students and family medicine residents during their psychiatry postings; 4) Continuing medical education of family physicians in AKTH and elsewhere should include skills acquisition in diagnosis, treatment and outcome of depression; 5) Further multicenter studies are needed to replicate the findings in this study to allow for generalization.

\section{Acknowledgements}

I wish to acknowledge Prof. O Udofia of University of Calabar Teaching Hospital my supervisor, Dr Lawal, of the Federal Neuropsychiatric Hospital, Yaba Associate Prof. Sale Shehu the former HOD Psychiatry, BUK/ AKTH and My colleagues resident doctors in the Dept of psychiatry and Family Medicine who contributed immensely for the successful completion of this work.

\section{References}

[1] World Health Organisation (2004) Global Burden of Disease. http://www.who.int/healthinfo/global_burden_disease/GBD_report_2004 update_full.pdf

[2] Alan, D.L., Colin, D.M., Majid, E., Dean, T.J. and Christopher, J.L.M. (2006) Global Burden of Disease and Risk Factors. A Co-Publication of Oxford University Press and the World Bank, 355.

[3] Morakinyo, O. (2002) The Nature and Diagnosis of Depressive Disorders in Africans. Handbook for Mental health posting. Obafemi Awolowo University, Ile Ife, 68-69.

[4] Ohaeri, J.U. and Jegede, R.O. (1991) Depression and the General Medical Practice. Medicare, 6, 7-11.

[5] Uwakwe, R. (2004) Pattern of Mental Disorders in Private General Practice: A Six Months Experience at Aguata, Nigeria. Journal of Biomedical Investigation, 2, 34-41. http://dx.doi.org/10.4314/jbi.v2i1.30378

[6] Okulate, G.T. (1999) Psychiatric Morbidity in Private General Practice in Lagos, Nigeria. Nigerian Quarterly Journal of Hospital Medicine, 9, 124-126. http://dx.doi.org/10.4314/nqjhm.v9i2.12392

[7] Gureje, O. and Simon, G.E. (1999) The Natural History of Somatisation in Primary Care. Psychological Medicine, 29, 669-676. http://dx.doi.org/10.1017/S0033291799008417

[8] Ihezue, U.H. and Khumaraswamy, N. (1986) Prevalence of Psychiatric Morbidity and Utilisation of Traditional Healers in General Outpatient Clinic. Acta Psychiatrica Scandinavia, 73, 395. http://dx.doi.org/10.1111/j.1600-0447.1986.tb02701.x

[9] Afolabi, M.O., Abioye-Kuteyi, E.A., Fatoye, F.O., Bello, I.S. and Adewuya, A.O. (2008) Pattern of Depression among Patients in a Nigerian Family Practice. South Africa Family Practice, 50, 63. http://dx.doi.org/10.1080/20786204.2008.10873701

[10] Qin, X., Wang, W., Jin, Q., Ai, L., Li, Y., Dong, G., Liu, L. and Phillips, M.R. (2008) Prevalence and Rates of Recognition of Depressive Disorders in Internal Medicine Outpatient Department of 23 General Hospitals in Shenyang, China. Journal of Affective Disorders, 110, 46-54. http://dx.doi.org/10.1016/j.jad.2007.12.237

[11] Kessler, L.G., Cleary, P.D. and Burke, J.D. (1985) Psychiatric Disorders in Primary Care. Results of Follow up Study. Archive of General Psychiatry, 42, 583-587. http://dx.doi.org/10.1001/archpsyc.1985.01790290065007

[12] Kirmayer, L.J., Robbins, J.M., Dworkind, M., et al. (1993) Somatisation and the Recognition of Depression and Anxiety in Primary Care. American Journal of Psychiatry, 150, 734-741. http://dx.doi.org/10.1176/ajp.150.5.734

[13] Lwanga, S.K. and Lemeshow, S. (1991) Sample Size Determination in Health Studies: A Practical Manual. WHO, Geneva, 15.

[14] All-on-depression-Help.com (2011) Information and Inspiration for Overcoming Depression, Hamilton Depression Rating Scale. www.all-on-depression-help.com/hamilton-depression-scale.html

[15] (2011) SCAN (Schedule for Clinical Assessment in Neuropsychiatry). Wikipedia, the Free Encyclopaedia. http://en.wikipedia.org/wiki/SCAN

[16] (2011) SPSS (Statiscal Package for Social Sciences). Wikipedia, The Free Encyclopaedia. http://en.wikipedia.org/wiki/SPSS 
[17] Coyne, J.C., Schwenck, T.L. and Fechner-Bates, S. (1995) Nondetection of Depression by Primary Care Physicians Reconsidered. General Hospital Psychiatry, 17, 3-13. http://dx.doi.org/10.1016/0163-8343(94)00056-J

[18] Simon, G.E. and von Korff, M. (1995) Recognition, Management, and Outcomes of Depression in Primary Care. Archive of Family Medicine, 4, 99-105. http://dx.doi.org/10.1001/archfami.4.2.99 